\title{
Correlation of Severity of ST Segment Elevation with Respect to the Site of Right Coronary Artery Lesion
}

\author{
Rabindra Simkhada' \\ 'Department of Cardiology, National Academy of Medical Sciences (NAMS), Bir Hospital, Kathmandu, Nepal.
}

\section{ABSTRACT}

Introduction: Electrocardiogram a widely available tool may predict infarct related artery in acute inferior wall myocardial infarction. Severity of ST segment elevation may correlate with proximity of lesion in right coronary artery.

Methods: Patient with acute ST segment elevation inferior wall myocardial infarction who underwent coronary angiogram was studied. Differences in electrocardiogram among right coronary and left circumflex groups were evaluated. Severity of ST segments elevation in relation to site of lesion in right coronary was studied.

Results: The mean age of presentation was $59.52 \pm 11.01$ years. Total $36(72 \%)$ were men. A total of $42(84 \%)$ had lesion in right and $8(16 \%)$ in left circumflex. Age, sex,diabetes,hypertension, smoking, dyslipidemia and physical activity showed no correlation with lesion in right or circumflex coronary artery. ST segment elevation in III $>$ II $(P=0.01)$, ST segment depression in AVL $>\mathrm{I}(\mathrm{P}<0.01)$ and ST elevation in V4R $(\mathrm{P}=0.04)$, correlated with right coronary lesion. Sum of ST elevation in inferior leads were $10.90 \pm 1.30 \mathrm{~mm}$ for proximal, $7.38 \pm 1.19 \mathrm{~mm}$ for mid and $5.50 \pm 0.53 \mathrm{~mm}$ for distal right coronary with significant correlation $(\mathrm{P}<0.01)$.

Conclusions: Electrocardiogram was reliable tool to difference right and left circumflex lesion. Severity of sum of ST segment elevations in inferior leads correlated with the proximity of lesion in right coronary.

Keywords: acute inferior myocardial infarction; electrocardiogram; infarct related artery.

\section{INTRODUCTION}

ST segment elevation myocardial infarction (STEMI) represents the most lethal form of Acute Coronary Syndrome (ACS). ${ }^{1}$ About one third of myocardial infarction (MI) are STEMI. ${ }^{2}$ Acute inferior STEMI is characterized by ST segment elevation in leads II, III, and aVF. Infarct related artery (IRA) of inferior $\mathrm{MI}$ can be right coronary artery (RCA) or left circumflex artery (LCX). ${ }^{3}$ RCA supplies several important structures in heart, so they can be involved if IRA is RCA.
Electrocardiogram (ECG) is a simple and easily available tool. Several ECG criteria has been recommended for the IRA prediction with variable results. ${ }^{4,5}$ Predicting the site of occlusion in RCA by ECG is worthwhile as proximal occlusion is likely to cause larger myocardial damage.

Correspondence: Dr. Rabindra Simkhada, National Academy of Medical Sciences (NAMS), Bir Hospital, Kathmandu, Nepal. Email: rsimkhada2001@yahoo.com, Phone: 9841249210. 
The objective of the study was to determine IRA focusing correlation between RCA lesion site and severity of ST segment elevation in inferior leads in inferior $\mathrm{Ml}$ in our setup.

\section{METHODS}

A cross-sectional prospective study was conducted at Department of Cardiology, Shahid Gangalal National Heart centre (SGNHC) Kathmandu from February to July 2013. Ethical approval was taken from the Institutional Review Board (IRB) of National Academy of Medical Sciences (NAMS) and the informed consent was obtained from all the participants.

All the participants needed to have had coronary angiogram (CAG) done either during the primary percutaneous intervention (PCl) or before discharge from hospital to be included in the study. Patients with previous history of coronary artery disease, with left bundle branch block, a paced rhythm, an accelerated Idioventricular rhythm or severe artifacts causing difficulty for accurate ST segment measurement were excluded. Patients who didn't go angiogram or with diffuse angiographic lesions involving more than one segment in RCA or involving both RCA and LCX were excluded. Patients who didn't give consent for the study were also excluded.

A total of 50 consecutive patients of acute ST segment elevation inferior wall MI were included. Among the patients who presented with clinical features suggestive of $\mathrm{MI}$, acute inferior wall STEMI was diagnosed on the basis of $\geq 1 \mathrm{~mm} \mathrm{ST} \mathrm{elevation} \mathrm{in} \mathrm{at} \mathrm{least} 2$ inferior leads ECG measured 0.08 seconds after the $\mathrm{J}$ points with reciprocal ST segment depression in I and $\mathrm{aVL}$ and rise of cardiac enzymes (CPK-MB or Troponin I). The patients were evaluated focusing the variables to be tested. Those who practice at least 30 minute of moderate exertional activity each day were considered physically active. ECGs were recorded at $25 \mathrm{~mm} / \mathrm{s}$ speed, and calibrated to $1 \mathrm{mV} / \mathrm{cm}$. The right sided ECG and posterior ECG was taken in all with the suspicion of RV infarction (ST elevation $\geq 1 \mathrm{~mm}$ in V4R) and posterior infarction (ST elevation $\geq 1 \mathrm{~mm}$ in V7-V9) respectively.

The patients were followed up for coronary angiogram. Angiograms were evaluated for IRA as RCA or LCX. $R C A$, further was categorized in proximal [from ostium to the first Acute Marginal $(A M)]$, mid (from First to last $A M$ ) or distal (from last $A M$ onwards). ${ }^{6}$ The lesion with highest degree of stenosis was accepted as culprit lesion.

Data were entered and analyzed using SPSS version 14 for windows. For demographic profiles frequencies and percentage distribution were calculated for each variable. Chi square test were used to detect the level of significance. Means were compared using one way ANOVA. $P$ values were calculated and values less than 0.05 were considered statically significant.

\section{RESULTS}

Among the 50 enrolled patients of acute inferior wall MI, majority $36(72 \%)$ were male. The age ranged between 33 to 82 years with mean age of presentation being $59.52 \pm 11.01$ years. Hypertension and diabetes were present in $20(40 \%)$ and $13(26 \%)$ respectively. A total of $19(38 \%)$ were current smoker (Table 1$)$.

\begin{tabular}{|ll|}
\hline $\begin{array}{l}\text { Table 1. Baseline characteristics of enrolled } \\
\text { subjects. }\end{array}$ \\
\hline Characteristics & Values \\
Age ( mean \pm SD) & $\begin{array}{l}59.52 \pm 11.01 \\
\text { years }\end{array}$ \\
Age Range & $33-82$ years \\
Sex male : female, No.(\%) & $36: 14(72 \%: 28 \%)$ \\
Hypertension, No.(\%) & $20(40 \%)$ \\
Diabetes, No.(\%) & $13(26 \%)$ \\
Smoker, No. (\%) & $19(38 \%)$ \\
Dyslipidemia, No. (\%) & $9(18 \%)$ \\
Physically inactive, No. (\%) & $21(42 \%)$ \\
\hline
\end{tabular}

Different forms of bradyarrhythmia were prevalent among the participants. A total of $16(32 \%)$ had sinus bradycardia, 5 (10\%) had complete heart block. Right sided and posterior ECG revealed 15 (30\%) ST elevation in V4R and 8 (16\%) ST elevation V7-V9 leads (Table 2).

Table 2. Common complications noted in study subjects.

\begin{tabular}{|ll|}
\hline Title & N (\%) \\
Sinus Bradycardia & $16(32 \%)$ \\
Complete Heart block & $5(10 \%)$ \\
$2^{\text {nd }}$ degree AV block & $3(6 \%)$ \\
ST $\uparrow$ V4R & $15(30 \%)$ \\
ST $\uparrow$ V7-V9 & $8(16 \%)$ \\
\hline
\end{tabular}

A total of $42(84 \%)$ subjects had lesion in RCA and 8 $(16 \%)$ had lesion in LCX.

There was no significant difference in the baseline characteristics between the RCA and LCX group. Age, sex, presence of diabetes and hypertension, smoking, known dyslipidemia and physical activity status showed no correlation to lesion in right or left circumflex coronary artery (Table 3 ). 


\begin{tabular}{|c|c|c|c|}
\hline Characteristics & $\begin{array}{l}\text { RCA (No. } \\
=42)\end{array}$ & $\begin{array}{l}\text { LCX (No. } \\
=8 \text { ) }\end{array}$ & $\begin{array}{l}P \\
\text { value }\end{array}$ \\
\hline $\begin{array}{l}\text { Age mean } \pm \\
S D, \text { years }\end{array}$ & $\begin{array}{l}60.07 \pm \\
11.53\end{array}$ & $56.63 \pm 7.67$ & 0.83 \\
\hline $\begin{array}{l}\text { Sex male/ } \\
\text { female (No.) }\end{array}$ & $30 / 12$ & $6 / 2$ & 0.64 \\
\hline Diabetes (No.) & 10 & 3 & 0.34 \\
\hline $\begin{array}{l}\text { Hypertension } \\
\text { (No.) }\end{array}$ & 16 & 4 & 0.40 \\
\hline Smoking (No.) & 15 & 4 & 0.35 \\
\hline $\begin{array}{l}\text { Dyslipidemia } \\
\text { (No.) }\end{array}$ & 8 & 1 & 0.55 \\
\hline $\begin{array}{l}\text { Physically } \\
\text { Inactive (No.) }\end{array}$ & 17 & 4 & 0.45 \\
\hline
\end{tabular}

Among the three electrocardiographic criteria compared between RCA and LCX group, ST segment elevation in III $>$ II and ST segment depression in AVL> I was more when RCA was IRA ( $P=0.01$ and $<0.01$ respectively). Similarly presence of ST elevation in V4Rcorrelated significantly $(\mathrm{P}=0.04)$ with $\mathrm{RCA}$ lesion (Table 4).

Table 4. Comparison of ECG criteria between RCA and LCX group.

\begin{tabular}{|llll|}
\hline Criteria & $\begin{array}{l}\text { RCA No. } \\
(\%)\end{array}$ & $\begin{array}{l}\text { LCX No. } \\
(\%)\end{array}$ & P value \\
$\begin{array}{l}\text { ST elevation } \\
\text { III }>\text { II }\end{array}$ & $\begin{array}{l}39 \\
(92.85 \%)\end{array}$ & $3(37.5 \%)$ & 0.01 \\
$\begin{array}{l}\text { ST depression } \\
\text { aVL }>\text { I }\end{array}$ & $\begin{array}{l}40 \\
(95.23 \%)\end{array}$ & $2(25 \%)$ & $<0.01$ \\
ST elevation & 15 & $0(0 \%)$ & 0.04 \\
V4R & $(35.71 \%)$ & & \\
\hline
\end{tabular}

Out of 42 participants who had RCA as IRA, 21 (50\%) had lesion in proximal, $13(31 \%)$ in mid and $8(19 \%)$ in distal RCA.The sum of total ST segment elevation of inferior leads (II + III + aVF) for proximal RCA was $10.90 \pm 1.30 \mathrm{~mm}$. It was $7.38 \pm 1.19 \mathrm{~mm}$ formid and $5.50 \pm 0.53 \mathrm{~mm}$ for distal groups RCA. With statically significance $(P<0.01)$, the values were morein proximal followed by mid and distal groups (Table 5).

\begin{tabular}{|lll|}
\hline $\begin{array}{l}\text { Table 5. Total ST segment elevation in inferior } \\
\text { leads, (II }+ \text { III }+ \text { aVF). }\end{array}$ & \\
\hline Site & Values & P value \\
Proximal RCA & $10.90 \pm 1.30 \mathrm{~mm}$ & $<0.01$ \\
Mid RCA & $7.38 \pm 1.19 \mathrm{~mm}$ & $<0.01$ \\
Distal RCA & $5.50 \pm 0.53 \mathrm{~mm}$ & $<0.01$ \\
\hline
\end{tabular}

\section{DISCUSSION}

Acute inferior wall Myocardial Infarction (MI) is a significant cardiovascular problem. It occurs due to lesion either in RCA or LCX. Certain abnormalities have been shown to be common in inferior wall MI. This study found sinus bradycardia in $16(32 \%)$ patients. Complete heart block ( $\mathrm{CHB})$ was found in $5(10 \%)$. Zahid Fida found sinus bradycardia in $29.6 \%$ and $\mathrm{CHB}$ in $7.4 \%$ of patients. ${ }^{7}$ Similarly, $12.7 \%$ of $\mathrm{CHB}$ was found in a study by Man Hong Jim et al. ${ }^{8}$

This study found ST elevation in V4R in 30\% and V7V9 in $16 \%$ cases. A study had shown ST elevation in V4R in $54 \%$ cases and posterior $\mathrm{Ml}$ had been reported in $15-21 \%$ of acute $\mathrm{Ml}$ generally accompanied by inferior/lateral wall MI. ${ }^{9,10}$

Present study found $84 \%$ RCA and $16 \%$ LCX as IRA in acute ST segment elevation inferior wall $\mathrm{MI}$ in our set up. Result is comparable to previous studies. Al Hussain Abbase et al found 82.14\% RCA as IRA. ${ }^{11}$ Similarly Niels $\mathrm{J}$ Verouden et al found RCA as a culprit in $79 \% .{ }^{12}$ There was no significant difference in baseline characteristics in between the RCA and LCX group. Chun-Yen Chiang et al found similar results. ${ }^{13}$ Another study showed LCX occlusion significantly higher in older age with no significant differences in other baseline characterstics. ${ }^{7}$

The criteria of ST elevation III $>$ II and ST depression $\mathrm{aVL}>\mathrm{I}$ were more likely to be present in RCA group. There are several studies published using various criteria for the predilection of IRA. ${ }^{14-16} \mathrm{Herz}$ el al found $84 \%$ sensitivity and $88 \%$ positive predictive value for the first and $82 \%$ sensitivity and $80 \%$ positive predictive value for the second criteria mentioned above. When both above criteria were combined the specificity and positive predictive value both were $100 \% .{ }^{17}$ Al Hussain et al also reported a significant correlation of above mentioned criteria for determination of IRA with $P$ values $<0.001$ in both cases. ${ }^{11}$ The study found ST elevation $\mathrm{V} 4 \mathrm{R}$ also had a positive correlation with IRA as RCA ( $P=0.04)$. Braat et al showed specificity and positive predictive value of $100 \%$ and sensitivity of $59 \%$ of the criterion of ST elevation V4R $\geq 1 \mathrm{~mm} .^{5}$

The sum of ST elevation in inferior leads $(\mathrm{II}+\mathrm{III}+$ aVF) in the present study was $10.90 \pm 1.30 \mathrm{~mm}$ for proximal, $7.38 \pm 1.19 \mathrm{~mm}$ for $\mathrm{mid}$ and $5.5 \pm 0.53$ $\mathrm{mm}$ for distal RCA. This study showed a positive correlation of sum of ST segment elevation in inferior leads to the proximity of lesion in RCA ( $P<0.01)$. Moazzam Ali Naqvi et al showed sum of ST elevation of $12.55 \pm 1.38 \mathrm{~mm}$ for proximal $8.39 \pm 0.89 \mathrm{~mm}$ for mid and $6.00 \pm 0.54 \mathrm{~mm}$ for distal RCA with significant correlation $(P<0.01) .{ }^{18}$ Similarly in a study by Alim Erdem et al found the sum of ST elevation of $12.61 \pm$ $3.79 \mathrm{~mm}$ for proximal, $6.88 \pm 1.20 \mathrm{~mm}$ for mid and $5.05 \pm 0.97 \mathrm{~mm}$ for distal RCA. ${ }^{6}$ The study of Ala Hussain Abbase et al found the sum of ST segment elevation of $11.7 \pm 1.8 \mathrm{~mm}$ in proximal, $7.2 \pm 0.97$ 
$\mathrm{mm}$ in mid and $5.8 \pm 0.2 \mathrm{~mm}$ in distal RCA lesions. ${ }^{11}$ The findings of positive correlation of severity of sum of ST segment elevation in inferior leads seen in our set up was in consistent with the previously reported literatures.

The study had certain limitations. This was a single center based study done within a short time frame including small number of participants. The study only included clear cut lesions of either RCA or LCX artery. Cases with lesion in both of arteries can have different ECG manifestations. Larger studies to address the above shortcoming is encouraged and expected in future.

\section{CONCLUSIONS}

ECG, an easily available and essential tool for the diagnosis of acute myocardial infarction could predict the infarct related artery in acute ST elevation inferior wall $\mathrm{MI}$ if it is RCA or LCX. The sum of ST segment elevation in inferior leads correlated with the site of lesion in right coronary artery in our set up, the more proximal lesions had greater values. These findings will help to formulate the plan for their further management.

\section{REFERENCES}

1. Kim MC, Kini AS, Fuster V. Definitions of acute coronary syndromes. In: Fuster V, Wals RA, Harrington RA, editors. Hurst's The Heart. 13 ${ }^{\text {th }}$ ed. New York: McGraw-Hill; 2011. Vol II. p. 1287-95.

2. Lloyd JD, Adams R, Carnethon M, De-Simone G, Ferguson TB, Flegal K et al. Heart disease and stroke statistics- 2009 update: a report from the American heart Association Statistics committee and Stroke Statistics subcommittee. Circulation. 2009;119:480-6.

3. Parikh A, Shah PK. New insights into the electrocardiogram of acute myocardial infarction. In: Gersh BJ, Rahimtoola SH. Acute Myocardial Infarction. $2^{\text {nd }}$ ed. New York: Chapman \& Hall; 1997. p. 163-88.

4. Hasdai D, Birnbaum Y, Herz I, Sclarovsky S, Mazur A, Solodky A. ST-segment depression in lateral limb leads in inferior wall acute myocardial infarction: implications regarding the culprit artery and the site of obstruction. Eur Heart J. 1995;16:1549-53.

5. Braat SH, Brugada P, De-Dulk K, Zwaan CD, Coenegracht T, Wellens HJ. Value of lead V4R for recognition of the infarct coronary artery in acute inferior myocardial infarction. Am J Cardiol. 1984;53:1538-41.

6. Erdem A, Yilmaz MB, Yalta K, Turgut OO, Tandogan I. The severity of ST segment elevation in acute inferior myocardial infarction: Does it predict the presence of a proximal culprit lesion along the right coronary artery course? Anatol J Cardiol. 2007;7:189-90.

7. Fida Z. Complications with acute inferior wall myocardial infarction. Journal of postgraduate Medical Institute. 2004;18:202-5.

8. Jim MH, Chan AO, Tse HF, Barold SS, Lau CP.Clinical and Angiographic Findings of Complete Atrioventricular Block in Acute Inferior Myocardial Infarction.Ann Acad Med Singapore. 2010;39:185-90.

9. Zehender M, Kasper W, Kauder E, Schonthaler M, Geibel A, Olschewski $\mathrm{M}$ et al. Right ventricular infarction as an independent predictor of prognosis after acute myocardial infarction. N Engl J Med. 1993;328:981-8.
10. Gorsolen EO, Verheugt FW, Meursing BT, Ophius AJ.Posterior myocardial infarction: the dark side of the moon. Neth Heart J. 2007;15:16-21.

11. AbbaseAH, Al-Jumaily HS.Electrocardiographic Criteria for Predicting Site of Coronary Artery Occlusion in Acute Inferior Wall Myocardial Infarction. Medical Journal of Babylon. 2011;8:286-94.

12. Niels JV, Kurdo B, Karel TK, Jose PH, Jan B, Rane J, et al. Distinguishing the right coronary artery from the left circumflex coronary artery as the infarct related artery in patients undergoing primary percutaneous coronary intervention for acute inferior myocardial infarction. Europace. 2009;11:1517-21.

13. Chiang CY, Ku PM, Huang TY, Cheng CC, Wo WS, Chen ZC et al.EKG Criteria Predict Infarct-related Artery of Inferior Wall AMI. Acta Cardiol Sin. 2006;22:67-74.

14. Bairey CN, Shah PK, Lew AS, Hulse S. Electrocardiographic differentiation of occlusion of the left circumflex versus the right coronary artery as a cause of inferior acute myocardial infarction. Am J Cardiol. 1987;60:456-9.

15. Chia BL, Yip JW, Tan HC, Lim YT. Usefulness of ST elevation II/III ratio and ST deviation in lead I for identifying the culprit artery in inferior wall acute myocardial infarction. Am J Cardiol. 2000;86:341-3.

16. Zimetbaum PJ, Josephson ME. Use of the electrocardiogram in acute myocardial infarction. N Engl J Med. 2003;348:933-40.

17. Herz I, Assali AR, Adler Y, Solodky A, Sclarovsky S. New electrocardiographic criteria for predicting either the right or left circumflex artery as the culprit coronary artery in inferior wall acute myocardial infarction. Am J Cardiol. 1997;80:1343-5.

18. Naqvi MA, Ali M, Hakeem F, Masood A, Akram Z. Correlation of severity of ST segment elevation in acute inferior wall myocardial infarction with the proximity of right coronary artery disease.J Ayub Med Coll Abbottabad. 2008;20:82-5. 